\section{Cryptococcal small-bowel obstruction in an HIV-positive patient}

\author{
D H Nawabi ${ }^{1}$ \\ L Ffolkes ${ }^{2} \quad$ A O'Bichere ${ }^{1}$
}

J R Soc Med 2005;98:513-514

Meningitis and pulmonary infections are common manifestations of cryptococcosis but gastrointestinal involvement is rare.

\section{CASE HISTORY}

A woman aged 39 was admitted with cryptococcal meningitis. Her CD4 count was low at $30 \times 10^{6} / \mathrm{L}$ but she responded to intravenous amphotericin $(0.7 \mathrm{mg} / \mathrm{kg}$ per day), flucytosine ( $25 \mathrm{mg} / \mathrm{kg}$ per day) for 2 weeks and oral fluconazole ( $800 \mathrm{mg}$ per day) thereafter. Four weeks after admission, however, she developed progressive abdominal distension with pain and vomiting. CT demonstrated features consistent with small-bowel obstruction but no cause was identified radiologically. Despite a trial of conservative management with nil orally, nasogastric tube aspiration and fluid and electrolyte replacement, her symptoms persisted. At exploratory laparotomy a $3 \mathrm{~cm}$ stricture of the distal ileum was seen to be causing small-bowel obstruction (Figure 1). It was resected and bowel continuity was restored by end-to-end hand-sewn anastomosis. Histological examination of the stricture showed infiltration of the intestinal wall by cryptococci with a florid inflammatory response (Figure 2). Postoperative recovery was uneventful.

\section{COMMENT}

Fungal infection is a common affliction of HIV-positive patients because of their immunocompromised state and poor general health. Systemic infection with Cryptococcus neoformans, an encapsulated yeast, is the most lethal of all AIDS-related fungal infections. ${ }^{1}$ The organism is primarily transmitted via the respiratory route but can infect any organ of the body by haematogenous spread. It has a predilection for the central nervous and respiratory

\footnotetext{
${ }^{1}$ Colorectal Unit, The Middlesex Hospital (University College London Hospitals), London W1T 3AA; 'Department of Histopathology, University College Hospital, London WC1E 6AU, UK

Correspondence to: Mr A O'Bichere

E-mail: austin.obichere@uclh.org
}

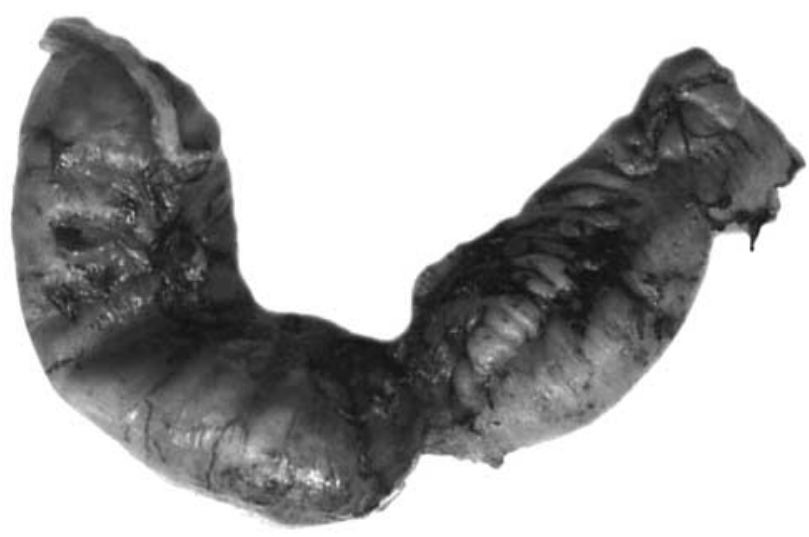

Figure 1 Resected small bowel segment with stricture

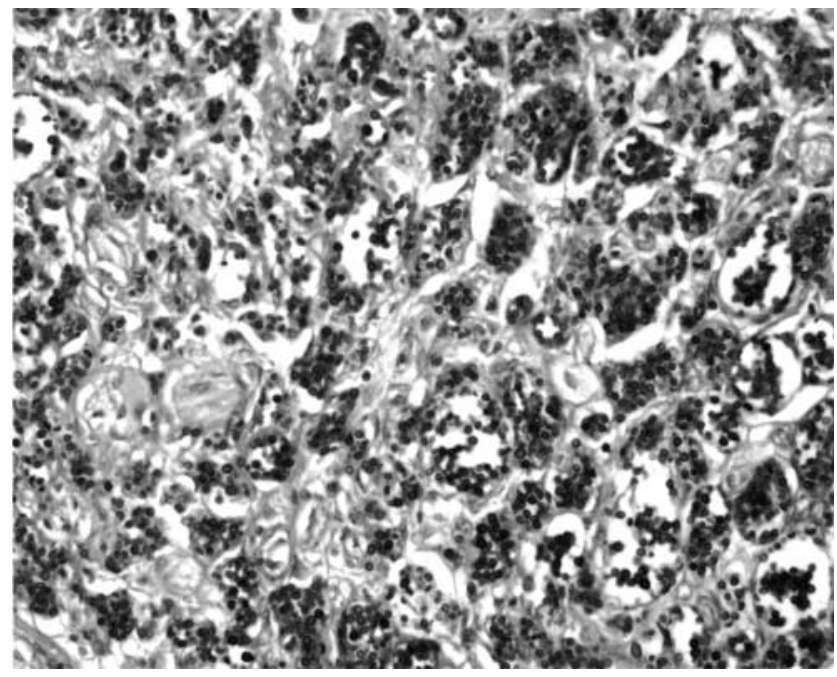

Figure 2 Section through stricture showing florid infiltrate of foamy histiocytes and numerous DPAS (diastase-resistant periodic acid-Schiff) positive cryptococci (mucicarmine positive)

systems. ${ }^{2}$ Clinically, gastrointestinal cryptococcosis is rare even in the context of HIV infection; however, in one necropsy series, gastrointestinal involvement was seen in 8 of 24 patients with disseminated cryptococcal infection. ${ }^{3}$

Small-bowel obstruction due to cryptococcosis has been reported in an HIV-negative patient treated for cryptococcal meningitis. A jejunal stricture developed where cryptococcal peritoneal granulomas had caused extrinsic compression of the bowel. ${ }^{4}$ Other reports have described cryptococcal peritonitis, but without histological confirmation. ${ }^{5}$ By contrast, in the present HIV-positive patient, the ileal stricture was proven histologically to be the result of cryptococcal infection within the bowel wall, without evidence of peritonitis. 


\section{REFERENCES}

1 Perfect JR, Casadevall A. Cryptococcosis. Infect Dis Clin North Am 2002;16:837-74

2 Lewis JL, Rabinovich S. The wide spectrum of cryptococcal infections. Am J Med 1972;53:315-22
3 Washington K, Gottfried MR, Wilson ML. Gastrointestinal cryptococcosis. Mod Pathol 1991;4:707-11

4 Gordon SM, Gal AA, Amerson JR. Granulomatous peritoneal cryptococcomas. An unusual sequela of disseminated cryptococcosis. Arch Pathol Lab Med 1994;118:194-5

5 Poblete RB, Kirby DB. Cryptococcal peritonitis: report of a case and review of the literature. Am J Med 1987;82:665-7

\section{Pyosalpinx in a man}

\section{K Baig ${ }^{1} \quad J$ Padmanabhan ${ }^{1} \quad$ T Liston²}

J R Soc Med 2005;98:514

True hermaphroditism is a rare condition, usually diagnosed soon after birth. ${ }^{1}$ In an adult, the male external genitalia may look normal.

\section{CASE HISTORY}

A man of 28 reported right iliac fossa pain for the past week, worsening progressively in the previous 24 hours. In earlier life he had had a hypospadias repair and a left orchidopexy. Clinically the signs indicated acute appendicitis but at operation the appendix was normal; present, however, was a normally formed uterus with a vaginal remnant and a right fallopian tube which was tense and filled with pus, (no left ovary was seen). Appendicectomy and a right salpingectomy were performed and histology confirmed pyosalpinx; no ovarian tissue was identified. Subsequent pelvic MRI showed a uterus with thin myometrium and a larger than normal endometrium but no prostatic or ovarian tissue.

The patient later developed a left inguinal hernia and underwent exploration of his left groin. An adherent mass just above the testis was excised and histology confirmed it to be the inflamed left fallopian tube. Testicular biopsy showed a varying degree of spermatogenesis but no spermatozoa. No ovarian tissue was seen and the right gonad was never found. The patient's karyotype was XY. In

Departments of ${ }^{1}$ General Surgery and ${ }^{2}$ Urology, Worthing Hospital, Worthing, West Sussex BN11 2DH, UK

Correspondence to: $\mathrm{M} \mathrm{K}$ Baig

E-mail: khurrum4@hotmail.com view of the possibility of developing uterine cancer he underwent a hysterectomy.

\section{COMMENT}

In true hermaphroditism the appearance of the external genitalia depends on which type of gonad is dominantfrom male to female with many intermediate variations. In the true hermaphrodite, testes have a suppressive effect on the mullerian structures, whereas ovotestis can behave as testis or an ovary. The factor responsible for testicular descent is unlikely to be androgens from the testis; this is illustrated by the congenital adrenal hyperplasia, attributable to 21-hydroxylase deficiency, that occurs in genotypic females.

Embryological development of the genitourinary system is complex. In a normal male child, mullerian structures have regressed and the Wolfian structures (vas deferens, epididymis, seminal vesicles) have developed under the influence of testosterone from the Leydig cells in the fetal testis. Regression of the mullerian structures is caused by mullerian inhibitory substance (MIS), produced by the Sertoli cells at about 6-8 weeks of fetal life. ${ }^{2}$ It acts on the target tissues by local diffusion and not by endocrine effect. ${ }^{3}$ The importance of this fact is that it primarily inhibits the mullerian structures from developing on the same side, so a normal testis will prevent the mullerian structures developing on the same side; however, a poorly functioning dysgenetic testis will only partly prevent the same structures developing, permitting some tubal or uterine development. We believe that the patient reported here represents a late manifestation of mullerian duct syndrome, in which there is an abnormality of MIS production in otherwise normal testis.

\section{REFERENCES}

1 Lim DJ, Mullins D L, Stevens PS. Crossed ectopia of ovotestis in a case of true hermaphroditism. J Pediatr Surg 1996;31:1440-2

2 Aaronson IA. Sexual differentiation and intersexuality. In: Kelalis PP, King LR, Belman, eds. Clinical Paediatric Urology, 3rd edn. Philadelphia: WB Saunders, 1992:977-1014

3 Wright NB, Smith C, Rickwood AMK, Carty HML. Imaging children with ambiguous genitalia and intersex states. Clin Radiol 1995;50:823-9 